\title{
Amyloid-Beta Interaction with Mitochondria
}

\author{
Lucia Pagani and Anne Eckert \\ Neurobiology Laboratory for Brain Aging and Mental Health, Psychiatric University Clinics, University of Basel, \\ Wilhelm Klein-Straße 27, 4012 Basel, Switzerland
}

Correspondence should be addressed to Anne Eckert, anne.eckert@upkbs.ch

Received 22 November 2010; Accepted 22 December 2010

Academic Editor: Katsuhiko Yanagisawa

Copyright ( $) 2011$ L. Pagani and A. Eckert. This is an open access article distributed under the Creative Commons Attribution License, which permits unrestricted use, distribution, and reproduction in any medium, provided the original work is properly cited.

\begin{abstract}
Mitochondrial dysfunction is a hallmark of amyloid-beta(A $\beta)$-induced neuronal toxicity in Alzheimer's disease (AD). The recent emphasis on the intracellular biology of $\mathrm{A} \beta$ and its precursor protein $(\mathrm{A} \beta \mathrm{PP})$ has led researchers to consider the possibility that mitochondria-associated and/or intramitochondrial $\mathrm{A} \beta$ may directly cause neurotoxicity. In this paper, we will outline current knowledge of the intracellular localization of both $\mathrm{A} \beta$ and $\mathrm{A} \beta \mathrm{PP}$ addressing the question of how $\mathrm{A} \beta$ can access mitochondria. Moreover, we summarize evidence from $\mathrm{AD}$ postmortem brain as well as cellular and animal $\mathrm{AD}$ models showing that $\mathrm{A} \beta$ triggers mitochondrial dysfunction through a number of pathways such as impairment of oxidative phosphorylation, elevation of reactive oxygen species (ROS) production, alteration of mitochondrial dynamics, and interaction with mitochondrial proteins. In particular, we focus on $\mathrm{A} \beta$ interaction with different mitochondrial targets including the outer mitochondrial membrane, intermembrane space, inner mitochondrial membrane, and the matrix. Thus, this paper establishes a modified model of the Alzheimer cascade mitochondrial hypothesis.
\end{abstract}

\section{Introduction}

Although the hallmark lesions of the disease were described by Alois Alzheimer already in 1906-extracellular amyloid plaques mainly composed of amyloid-beta $(\mathrm{A} \beta)$ and intracellular neurofibrillary tangles (NFTs) built up of hyperphosphorylated tau-the molecular mechanisms underlying the disease are still unknown. However, more recently, energy deficiency and mitochondrial dysfunction have been recognized as a prominent, early event in Alzheimer's disease (AD) [1-11]. Successful development of Alzheimer cell culture models as well as single, double, and recently triple transgenic mouse models that mimic diverse aspects of the disease facilitated the investigation of pathogenic mechanisms in $\mathrm{AD}$ and particularly assisted in an understanding of the interaction of amyloid-beta $(\mathrm{A} \beta)$ with mitochondria. Mitochondria were found to be the target both for amyloid precursor protein (APP) that accumulates in the mitochondrial import channels and for $\mathrm{A} \beta$ that interacts with several proteins inside mitochondria and leads to mitochondrial dysfunction [12].

\section{Intracellular Localization of $\mathbf{A} \beta \mathbf{P P}$}

Amyloid precursor protein $(\mathrm{A} \beta \mathrm{PP})$ is a type 1 integral $110-130 \mathrm{kDa}$ glycoprotein containing a 40 or 42 amino acid sequence, respectively, called $\mathrm{A} \beta_{40}$ and $\mathrm{A} \beta_{42}$. $\mathrm{A} \beta \mathrm{PP}$ is ubiquitously expressed in human tissues and localizes at the plasma membrane as well as in several organelles, such as endoplasmic reticulum (ER), Golgi apparatus, and mitochondria (Figure 1) $[13,14]$. A $\beta$ PP can undergo two pathways of cleavage by secretases: a nonamyloidogenic pathway and an amyloidogenic pathway. In the nonamyloidogenic pathway, a first cut of $\mathrm{A} \beta \mathrm{PP}$ is catalyzed by $\alpha$ secretase, an enzyme that belongs to the ADAM family of disintegrin and metalloprotease and is particularly present in post-Golgi compartment or at the plasma membrane [15]. $\alpha$-secretase cleaves $\mathrm{A} \beta \mathrm{PP}$ within the $\mathrm{A} \beta$ sequence [16], forming the small membrane-anchored C83 fragment and $\operatorname{sA} \beta \mathrm{PP} \alpha$. The $\mathrm{C} 83$ fragment is subsequently cleaved by $\gamma$-secretase, a multimeric complex of presenilin proteins PS1 and PS2, nicastrin, anterior pharynx defective1, and presenilin enhancer 2 [17], to form P3 fragment and A $\beta P P$ 


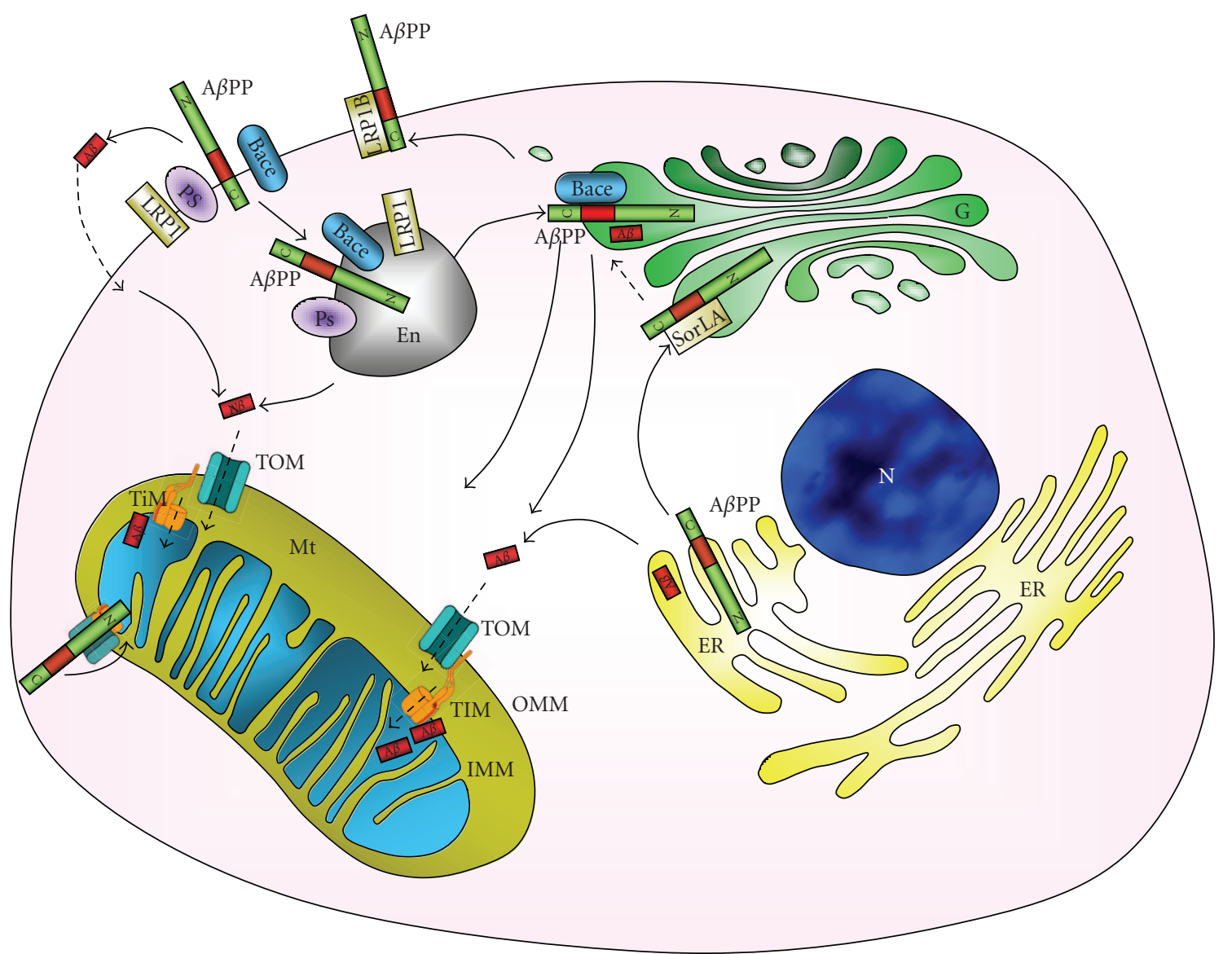

FIgURE 1: Intracellular localization of $\mathrm{A} \beta \mathrm{PP}$ and $\mathrm{A} \beta . \mathrm{A} \beta \mathrm{PP}$ is synthesised in the endoplasmic reticulum (ER) and is trafficked through Golgi network $(\mathrm{G})$, to the cell surface or to mitochondria (Mt). In the plasma membrane the apolipoprotein (Apo) receptor LRP1 forms a complex with $\mathrm{A} \beta \mathrm{PP}$, inducing the internalization of the amyloid precursor protein, together with other plasma membrane enzymes, such as the $\beta$-secretase BACE and the $\gamma$-secretase presenilin (PS): A $\beta$ is produced through amyloidogenic cleavage of A $\beta$ PP. The plasma membrane complex A $\beta$ PP with another Apo receptor, LRP1B, decreases the cellular uptake of A $\beta$ PP. Sources of mitochondrial A $\beta$ are the endosome (En) but also G and ER. G production of A $\beta$ is decreased by binding of A $\beta$ PP to another Apo receptor SorLA that blocks A $\beta$ PP in the early $\mathrm{G}$, counteracting A $\beta \mathrm{PP}$ cleavage pathways. $\mathrm{A} \beta$ enters into the mitochondrial matrix through TOM and translocase of the inner membrane (TIM) or is derived from mitochondria-associated $\mathrm{A} \beta \mathrm{PP}$ metabolism. $\mathrm{N}=$ nucleus, $\mathrm{OMM}=$ outer mitochondrial membrane, $\mathrm{IMM}=$ inner mitochondrial membrane.

intracellular domain (AICD) $[18,19]$. In the amyloidogenic pathway, $\mathrm{A} \beta \mathrm{PP}$ generates $\mathrm{A} \beta$ through the activity of $\beta$ secretase first and then $\gamma$-secretase, especially present in Golgi or in late endosomes following the reuptake from the cell surface. $\beta$-secretase whose activity was attributed to BACE [20] cleaves $A \beta P P$ at the $\mathrm{N}$-terminal of $\mathrm{A} \beta$ sequence forming a 99 amino acid fragment $\mathrm{C} 99$ and $\mathrm{sA} \beta \mathrm{PP} \beta$. $\mathrm{C} 99$ is subsequently cleaved by $\gamma$-secretase producing $\mathrm{A} \beta$ fragment and AICD [18]. Lipoprotein receptor LRP1 can interact with $\mathrm{A} \beta \mathrm{PP}$ (Figure 1), influencing $\mathrm{A} \beta \mathrm{PP}$ cleavage pathway: the interaction accelerates endocytosis of the complex $\mathrm{A} \beta \mathrm{PP}$ LRP1 and the adaptor Fe65 via clathrin-coated pits and the delivery to the late endosomal compartments for cleavage by $\beta$-secretase, to generate $\mathrm{A} \beta[21,22]$; this process can be counteracted by the slower rate of endocytosis LRP1B that sequestrates $\mathrm{A} \beta \mathrm{PP}$ at the plasma membrane, increasing $\alpha$-secretase activity $[23,24]$. SorLA, a further lipoprotein receptor, is also involved in $\mathrm{A} \beta \mathrm{PP}$ processing by binding $\mathrm{A} \beta \mathrm{PP}$ to the Golgi compartments, impairing the transition to the plasma membrane and blocking $\beta$-secretase activity (Figure 1) [25, 26].

With regard to localization of $\mathrm{A} \beta \mathrm{PP}$ in mitochondria, recent evidence is provided. Mainly the group of Devi and coworkers [27] demonstrated that $\mathrm{A} \beta \mathrm{PP}$ harbours a chimeric targeting signal consisting of an $\mathrm{N}$-terminal hydrophobic ER followed by a mitochondrial targeting signal. The positively charged residues at 40,44 , and 51 of $\mathrm{A} \beta \mathrm{PP}$ are critical components of the mitochondrial targeting signal. In addition, they showed that $\mathrm{A} \beta \mathrm{PP}$ formed stable approximately $480 \mathrm{kDa}$ complexes with the translocase of the outer mitochondrial membrane (OMM) 40 (TOM40) import channel and a supercomplex of approximately $620 \mathrm{kDa}$ with both mitochondrial TOM40 and the translocase of the inner mitochondrial membrane 23 (TIM23) import channel 
TI M23 in an N (in mitochondria)-C (out cytoplasm) orientation, probably due to a 70 amino acid long acidic domain [13]. Also in brain tissues of $\mathrm{AD}$ affected subjects $\mathrm{A} \beta \mathrm{PP}$ localized with mitochondria fraction, associated to TOM40 and TIM23 [27], in a translocation-arrested manner, that may prevent import of de novo synthesised nuclearencoded mitochondrial protein, such as subunits of the electron transport chain (ETC) [27]. Nevertheless, until very recently [12], it was believed that mitochondrial $\mathrm{A} \beta$ has to arrive from other sources, since $\mathrm{A} \beta \mathrm{PP}$ mitochondrial orientation presents $\mathrm{A} \beta$ outside the mitochondria [27].

\section{Intracellular Localization of $\mathbf{A} \boldsymbol{\beta}$}

In agreement with the intracellular localization of $\mathrm{A} \beta \mathrm{PP}$, cell biological studies have demonstrated that $\mathrm{A} \beta$ is generated in the ER, Golgi, and endosomal/lysosomal system (Figure 1). Reports indicate that $\mathrm{A} \beta x-42$ (truncated $\mathrm{A} \beta$ peptides with " $x$ " generally ranging from 1 and 11 ) is preferentially generated within the ER, whereas $A \beta 1-40 / 42$ peptides are predominantly made in the Golgi/trans-Golgi network (TGN) and packaged into post-TGN secretory vesicles [28, 29]. It is thought that the N-terminal truncation extends to a maximum length around amino acid 11 which renders $\mathrm{A} \beta$ even more insoluble, the latter pool of $\mathrm{A} \beta 42$ not being secreted [29].

Moreover, mitochondrial accumulation of $\mathrm{A} \beta$ has been shown in $\mathrm{AD}$ patient and $\mathrm{A} \beta \mathrm{PP}$ transgenic mouse brain $[4,28,30]$. In transgenic $\mathrm{A} \beta \mathrm{PP}$ mice expressing $\mathrm{A} \beta \mathrm{PP}$ $\mathrm{V} 717 / \mathrm{F}$ and the $\mathrm{A} \beta \mathrm{PP}$ Swedish mutation, mitochondrial $\mathrm{A} \beta$ accumulation increased at around 4 months of age, well before the formation of plaques [30]. In total, these findings are further in line with the recently proposed hypothesis of an intracellular $\mathrm{A} \beta$ toxicity cascade which suggests that the toxic $\mathrm{A} \beta$ species intervening in molecular and biochemical abnormalities may be intracellular soluble aggregates instead of extracellular, insoluble plaques $[4,31]$.

How can $A \beta$ access mitochondria? On the one hand, $\mathrm{A} \beta$ accumulation in mitochondria might derive from the ER/Golgi (Figure 1), since inhibition of protein secretion can modulate mitochondrial uptake $[30,32]$ or might derive from mitochondria-associated $\mathrm{A} \beta \mathrm{PP}[12]$ (Figure 1). It has been hypothesized that oligomeric $\mathrm{A} \beta$, with its sharp morphology in contrast to monomeric $\mathrm{A} \beta$, has the ability to permeabilize cellular membranes and lipid bilayers thereby entering organelles such as mitochondria [33, 34]. Of note, already early reports about the action of aggregated $\mathrm{A} \beta$ on membranes implicated increased membrane permeability elicited by fibrils $[35,36]$. These mechanisms might explain why aggregated $\mathrm{A} \beta$ preparations elicit effects on mitochondrial function, but not disaggregated $\mathrm{A} \beta$. Recent findings, however, indicate a specific uptake mechanism for $\mathrm{A} \beta$ by mitochondria rather than simply being adsorbed to the external surface of mitochondria $[37,38]$. In this model, $A \beta$ is taken up by mitochondria via the TOM complex. On the other hand, a new mechanistic view of mitochondria-related $\mathrm{A} \beta \mathrm{PP}$ metabolism was suggested very recently indicating that AICD, $\mathrm{P} 3$ peptide, and potentially $\mathrm{A} \beta$ are produced locally at the mitochondria. Hereby, mitochondrial A $\beta \mathrm{PP}$ is cleaved by
Omi in the intermembrane space and a concerted action of cytosolic $\alpha / \beta$ and mitochondrial $\gamma$-secretases [12].

\section{Mitochondria}

Mitochondria are dynamic ATP-generating organelles which contribute to many cellular functions including intracellular calcium regulation, alteration of reduction-oxidation potential of cells, free radical scavenging, and activation of caspasemediated cell death. ATP generation is accomplished through oxidative phosphorylation [7, 39-42]. ATP is subsequently used for a large repertoire of functions like intracellular calcium homeostasis, neurotransmitter production, and synaptic plasticity. Mitochondrial number is indeed very high in neurons, and mitochondria are especially enriched in synapses. Due to the limited glycolytic capacity of neurons, these cells are highly dependent on mitochondria function for energy production [43]. However, as the Pandora's Box, mitochondria are full of potentially harmful proteins and biochemical reaction centres. They may liberate reactive oxygen species (ROS) and free radicals. Thus, mitochondria are the major producers of ROS and at the same time major targets of ROS toxicity.

Mitochondria are composed of a double lipid membrane which structures four compartments, distinct by composition and function. The porous outer membrane (OMM) encompasses the whole organelle. It contains many proteins like import complexes and voltage-dependent anion channels (VDAC) responsible for the free passage of low molecular weight substances (up to $5000 \mathrm{Da}$ ) between the cytoplasm and the intermembrane space (IMS) (Figures 1 and 2) which represents a reservoir of protons establishing a proton electrochemical gradient across IMM that is needed for the production of ATP via ATPase (complex V). IMS contains proapoptotic proteins like cytochrome c, Smac/Diablo, EndoG, and Htra2/Omi. In contrast to the permeable OMM, the inner mitochondrial membrane (IMM), rich in cardiolipin, provides a highly efficient barrier to the flow of small molecules and ions, including protons. This membrane is invaginated into numerous cristae increasing cell surface area. It houses the respiratory enzymes of the electron transport chain (ETC), the cofactor coenzyme Q, and many mitochondrial carriers. In the matrix, different metabolic pathways take place including the tricarboxylic (TCA or Krebs) cycle (Figure 2).

Mitochondria generate energy by two closely coordinated metabolic processes: TCA and the oxidative phosphorylation (OXPHOS) (Figure 2). OXPHOS is made up of the ETC assembled in four enzymes (complex I to IV) as well as the F1F0-ATP synthase (complex V). Complex I, III, and IV are located in IMM as integral proteins whereas complex II is attached to the inner surface of IMM. These five enzymes are connected functionally by mobile electron acceptors and donors: ubiquinone and cytochrome c. Electrons from NADH and $\mathrm{FADH}_{2}$ are fed into complex I and II, respectively. Ubiquinone $\mathrm{Q}$ carries electrons from both complexes to complex II, and cytochrome $\mathrm{c}$ does it from complex III to IV reducing molecular oxygen to 


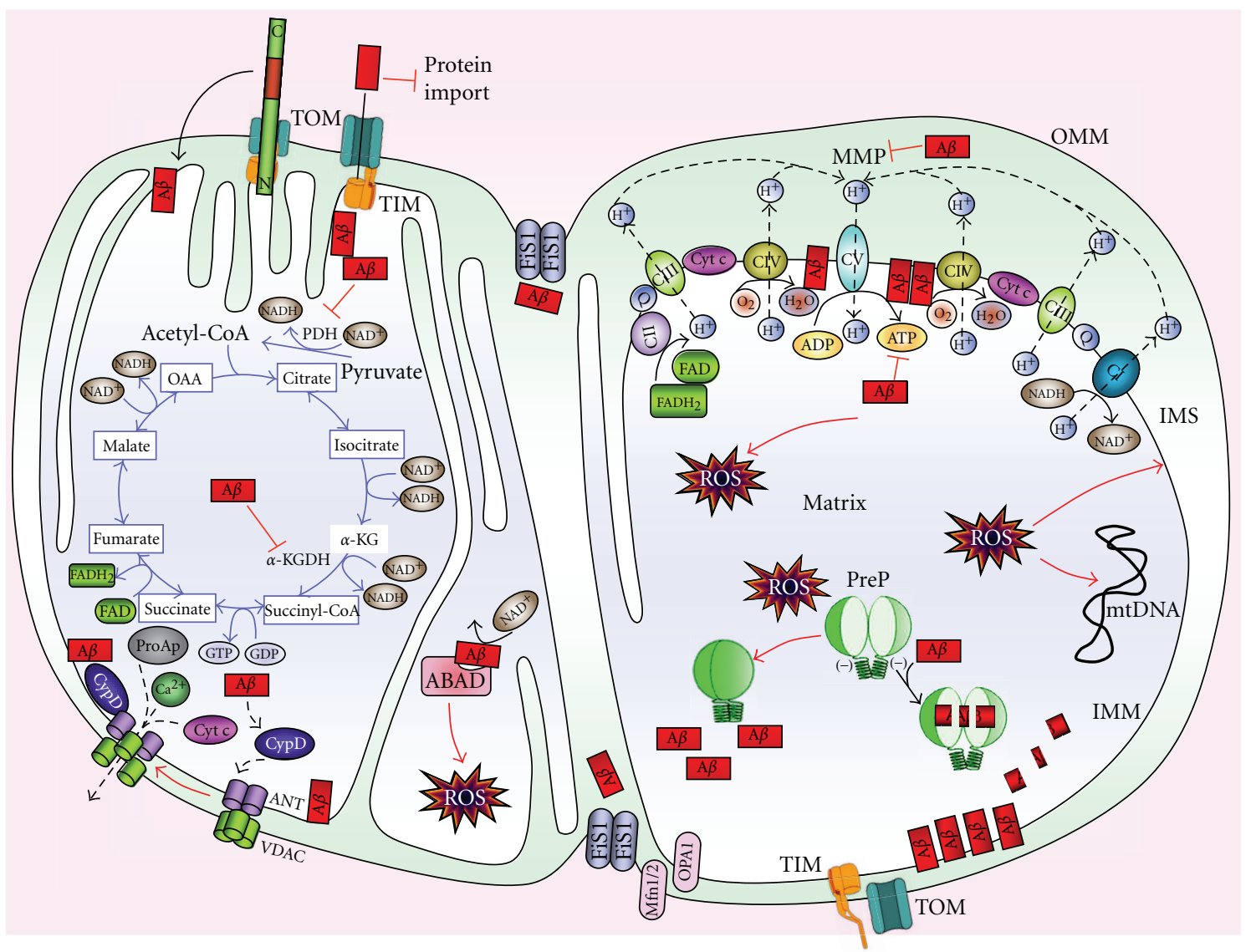

Figure 2: Mitochondrial targets of $\mathrm{A} \beta$. $\mathrm{A} \beta$ associated with mitochondria may be deposited at several locations. Although not present exclusively on the outer mitochondrial membrane, $\mathrm{A} \beta$ that might be present at that site might influence the interaction of multiple cytosolic proteins (including those of the bcl 2 family) with mitochondria, as well as affect the receptor binding of cargo targeted for import into the organelle via the TOM import machinery impeding mitochondrial entry to neosynthesised nuclear-encoded proteins such as subunits of the electron transport chain (ETC) complex IV (CIV). In the intramembrane space, A $\beta$ might affect the functions of both the inner and outer mitochondrial membrane by multiple mechanisms including modulating their permeability. In the mitochondrial matrix, $\mathrm{A} \beta$ might interact with important components of metabolic or antioxidant mechanisms. The interaction of $A \beta$ with the inner mitochondrial membrane would bring it into contact with respiratory chain complexes with the potential for myriad effects on cellular metabolism. Thus, $\mathrm{A} \beta$ affects the activity of several enzymes, such as pyruvate dehydrogenase (PDH) and $\alpha$-ketoglutarate dehydrogenase ( $\alpha$-KGDH), decreasing $\mathrm{NADH}$ reduction, and the ETC enzyme CIV, reducing the amount of hydrogen that is translocated from the matrix to the intermembrane space, thus impairing the mitochondrial membrane potential (MMP). The dysfunction of the ETC leads to a decreased CV activity and so to a lower ATP synthesis, in addition to increasing reactive oxygen species (ROS) production. ROS negatively influences presequence $\mathrm{P}$ (PreP) activity, blocking $\mathrm{A} \beta$ degradation, exacerbating mitochondrial $\mathrm{A} \beta$ presence. Moreover, ROS induce peroxidation of several mitochondrial macromolecules, such as mitochondrial DNA (mtDNA) and mitochondrial lipids, additionally impairing mitochondrial function. A $\beta$ binds $\mathrm{NAD}^{+}$pocket in $\mathrm{ABAD}$, blocking its activity and inducing further ROS production. $\mathrm{A} \beta$ also influences mitochondrial dynamic, by improving Fis 1 presence and activity, thus increasing mitochondrial fragmentation (fission protein: Fis 1; fusion proteins: Mfn $1 / 2$ and OPA1). Furthermore, $\mathrm{A} \beta$ binding to cyclophilin $\mathrm{D}(\mathrm{CypD})$ enhances the protein translocation to the inner membrane, favouring the opening of the mitochondrial permeability transition pore, formed by ANT and VDAC. Calcium storage in mitochondria is impaired, altering neuronal function; calcium is exported to the cytosol, as well as other apoptotic factors (ProAp) such as cytochrome c, apoptosis-inducing factor, Smac/DIABLO, endonuclease G, and procaspases, activating cellular apoptosis. IMM: inner mitochondrial membrane, IMS: intermembrane space, OMM: outer mitochondrial membrane.

water (Figure 2). As electrons are transferred along ETC, a fixed number of protons are pumped from the matrix into IMS establishing a electrochemical gradient characterized with a specific electrical potential (mitochondrial membrane potential = MMP: negative inside -150 to $-180 \mathrm{mV})$. The redox energy drives the synthesis of ATP from ADP as protons are transported back from IMS into the matrix via complex V. 


\section{Mitochondrial Targets of $A \beta$}

Growing evidence indicates that $\mathrm{A} \beta$ toxicity can be associated with the outer mitochondrial membrane, intermembrane space, inner mitochondrial membrane, and the matrix.

\subsection{OMM-IMM-IMS}

5.1.1. TOM-TIM Import Machinery. A working model postulates that $\mathrm{A} \beta$ and/or $\mathrm{A} \beta \mathrm{PP}$ interact with mitochondria by inhibiting protein import $[13,44]$. Import deficits are initially insufficient to impair mitochondrial integrity but over time cause mitochondrial dysfunction and further import deficits. $\mathrm{A} \beta$ may inhibit protein import by direct interactions with the import machinery or by indirect mechanisms. Given that multiple mitochondrial activities, including protein import itself, are dependent upon the import of nuclear-encoded proteins, it seems likely that even a modest decline in import could have potentially catastrophic consequences in the long-term. Furthermore, a decline in protein import seems to precede increased ROS and decreased mitochondrial membrane potential suggesting a gradual failure of mitochondria. Indeed, recent data from our group demonstrated mitochondrial dysfunction in a novel triple transgenic mouse model (pR5/A $\beta$ PP/PS2) triple $\mathrm{AD}$ mice - that combines both pathologic features of the disease in brain [1]. Using comparative, quantitative proteomics (iTRAQ) and mass spectroscopy, we found a massive deregulation of 24 proteins, of which one-third were mitochondrial proteins mainly related to complexes I and IV of the oxidative phosphorylation system (OXPHOS). Notably, deregulation of complex I was taudependent, while deregulation of complex IV was $A \beta$ dependent, both at the protein and activity levels. Together, these findings emphasize that $\mathrm{A} \beta$ and tau synergistically impair complex I function with aging. Notably, changes in the expression of complex IV subunits seem to be mainly related to $A \beta$. Indeed, a down regulation of several subunits of complex IV is essentially seen between pR5 and triple $A D$ mice, but not between $\mathrm{A} \beta \mathrm{PP} / \mathrm{PS} 2$ and ${ }^{\text {triple }} \mathrm{AD}$ mice. Interestingly, all of these deregulated proteins are nuclearencoded in agreement with the assumption of Sirk and coworkers [44].

5.1.2. Fusion and Fission Proteins. Mitochondria are dynamic organelles, undergoing continual fission, mediated by the protein Fis1 and dynamin-like protein1 (DLP1), and fusion, mediated by OPA1, Mfn1, and Mfn2 [45] (Figure 2). Unbalanced fusion leads to mitochondrial elongation, and unbalanced fission leads to excessive mitochondrial fragmentation, both of which impair the mitochondrial function [46, 47]. Mitochondrial fusion and fission have a different impact in mitochondria physiology: fission allows mitochondrial renewal, redistribution, and proliferation into synapses maintaining a pool of healthy mitochondria, while fusion facilitates mitochondrial movement and distribution across axons and synapses, suggesting a protective mechanism helping the maintenance of sufficient bioenergetic levels adjusted to situations with high-energy demands [48-50].
Several findings indicate that mitochondrial $\mathrm{A} \beta$ might play a role in impaired mitochondrial dynamics [6]. It could be demonstrated that neuroblastoma cells overexpressing human $\mathrm{A} \beta \mathrm{PP}$ bearing the Swedish double mutation (A $\beta$ PPsw) showed a higher percentage of highly fragmented and slower mitochondria compared to control cells. Moreover, MMP and ATP produced by mitochondria were reduced in $\mathrm{A} \beta \mathrm{PPsw}$ cells compared to control cells, suggesting vice versa a direct effect of mitochondrial dynamic on the function of the organelle. In particular, proteins involved in mitochondrial dynamics were present at different levels in $\mathrm{A} \beta \mathrm{PPsw}$ cells compared to control cells. Thus, in A $\beta$ PPsw cells, the balance between mitochondrial fusion and fission was shifted to enhanced fission which was accompanied by increased protein levels of fission proteins such as Fis-1 and reduced levels of fusion proteins like OPA1 and DLP1. In agreement with these in vitro findings, an abnormal distribution of mitochondria was also found in pyramidal neurons of AD-affected individuals [51-53].

Altered mitochondrial dynamics might be due to enhanced nitrosative stress generated by $A \beta$, such as $S$ nitrosylation of DLP1. This modification can disturb the balance between fission and fusion of mitochondria in favour of mitochondrial fission followed by mitochondrial depletion from axons and dendrites and subsequently synaptic loss $[54,55]$.

\subsection{IMM}

5.2.1. ETC: OXPHOS, ATP, and ROS. Early energy dysfunction characterized by a decreased mitochondrial membrane potential, ATP level, and complex IV activity has been reported for 3-and 6-month-old $\mathrm{A} \beta \mathrm{PP}$ transgenic mice (A $\beta$ PP; Swedish (KM670/671NL) and London (V717I) mutation) [3]. These mice showed also increased levels of 4-hydroxynonenal (HNE), a marker of lipid oxidation, and reduced activity of $\mathrm{Cu} / \mathrm{Zn}$ superoxide dismutase (SOD) [56]. Interestingly, mitochondrial defects such as the decrease of complex IV activity in 3-month-old A $\beta$ PP transgenic mice were already observed in the absence of plaques, but in the presence of increased $A \beta$ levels in brain $[3,57]$. Furthermore, an age-dependent impairment of oxygen consumption such as a decrease of state 3 and uncoupled respiration were observed in $\mathrm{A} \beta \mathrm{PP}$ transgenic mice compared to age-matched controls $[3,30,58]$. In addition, $\mathrm{A} \beta \mathrm{PP} / \mathrm{PS} 1$ transgenic mice, which in contrast to $\mathrm{A} \beta \mathrm{PP}$ transgenic mice exhibit $\mathrm{A} \beta$ plaques already at an age of 3 months, presented stronger reductions in mitochondrial membrane potential and ATP levels compared to age-matched $\mathrm{A} \beta \mathrm{PP}$ transgenic mice. Consequently, $A \beta$-dependent mitochondrial dysfunction starts already at a very young age and accelerates substantially with increasing age as does $\mathrm{A} \beta$ plaque load [59].

The development of sophisticated proteomic methods allowed the examination of synaptosomal fractions from $\mathrm{A} \beta \mathrm{PP}$ transgenic mice (Tg2576) and revealed a massive neuronal decay and synapse loss as the final consequence from all pathological changes occurring in $\mathrm{AD}$ [18]. Additional studies revealed significant differences in mitochondrial hsp70 and protein subunit composition of respiratory 
chain complexes I and III in this transgenic mouse model [58].

In a new triple $\mathrm{AD}(\mathrm{pR} 5 / \mathrm{A} \beta \mathrm{PP} / \mathrm{PS} 2)$ mouse model, we showed first of all that $\mathrm{A} \beta$ and tau act synergistically in amplifying mitochondrial respiratory deficits, mainly of complex I and IV activities. Thereby, hyperphosphorylated tau may drive a vicious cycle within the $\mathrm{A} \beta$ cascade. Remarkably, deregulation of complex I was related to tau, whereas deregulation of complex IV was A $\beta$ dependent, both at the protein and activity levels. The synergistic effects of $A B$ and tau led already at the age of 8 months to a depolarized mitochondrial membrane potential in the triple AD mice. Additionally, we found that age-related oxidative stress at 12 months of age may exaggerate the dysfunctional energy homeostasis and synthesis of ATP and, in turn, take part in the vicious cycle that finally leads to cell death [60]. Our data complement those obtained in another triple transgenic mouse model 3xTg-AD (P301Ltau/A $\beta$ PP/PS1) [61]. Yao and colleagues described age-related bioenergetic deficits in female 3xTg-AD mice aged from 3 to 12 months [62]. They found a decreased activity of regulatory enzymes of the OXPHOS (pyruvate dehydrogenase (PDH) and cytochrome $c$ oxidase $(\mathrm{COX}))$ and increased oxidative stress and lipid peroxidation. Most of the effects on mitochondria were seen at the age of 9 months, whereas mitochondrial respiration was significantly decreased with 12 months of age. Importantly, mitochondrial bioenergetic deficits precede the development of $\mathrm{AD}$ pathology in the $3 \mathrm{xTg}-\mathrm{AD}$ mice.

5.2.2. Cyclophilin D. Mitochondrial A $\beta$ may interact with Cyclophilin D (CypD), an integral part of the mitochondrial permeability transition pore ( $\mathrm{MPTP}$ ) which potentiates free radical production, causes synaptic failure, and promotes the opening of the mPTP leading to apoptosis [63].

CypD, a peptidylprolyl isomerase $\mathrm{F}$, normally resides in mitochondrial matrix and is involved in apoptosis and necrosis. It has been demonstrated that CypD is able to form complexes with $\mathrm{A} \beta$ within mitochondria of cortical neurons from APP transgenic mice, increasing the translocation of CypD from the matrix to the inner membrane (Figure 2) [64]. The translocation of CypD represents a first step in the opening of mPTP and involves the binding of CypD with adenine nucleotide translocase [65-69]. mPTP opening can lead to matrix swelling, dissipation of the inner membrane potential, and generation of ROS, with subsequent rupture of the outer membrane and a nonspecific release of intermembrane space proteins into the cytosol, such as cytochrome c, apoptosis-inducing factor, Smac/DIABLO, endonuclease $\mathrm{G}$, and procaspases, that will activate several signal transduction pathways such as apoptosis [70-75]. Furthermore, in $\mathrm{A} \beta \mathrm{PP}$ transgenic mice the abrogation of CypD was able to attenuate $\mathrm{A} \beta$-mediated abnormal mitochondrial dysfunction, such as calcium-induced mitochondrial swelling, lowered mitochondrial calcium uptake capacity, and impaired mitochondrial respiratory function [64]. Moreover, a correlation was found between levels of CypD in mitochondria and resistance to the opening of mPTP induced by calcium $[76,77]$, further supporting an active role of CypD in neuronal loss caused by $\mathrm{A} \beta$.

\subsection{Matrix}

5.3.1. The Tricarboxylic Acid Cycle (TCA or Krebs Cycle). Impairment in the activity and levels of several mitochondria enzymes involved in the Krebs cycle was reported since the early 80's (Figure 2). Perry and colleagues observed a reduction in pyruvate dehydrogenase (PDH), ATP-citrate lyase, and acetoacetyl-CoA thiolase in postmortem brain tissues of AD-affected subjects and correlated the decrease of these enzymes to the decreased production of acetylcoenzyme A and cholinergic defects that are observed in $\mathrm{AD}$ [78]. A frontal cortex deficiency in PDH activity was also observed in another cohort of brain tissues from AD patients [79]. Moreover, a reduced activity of thiamine-pyrophosphatedependent enzymes, such as $\alpha$-ketoglutarate dehydrogenase $(\mathrm{KGDH})$, was observed in brain tissues $[80,81]$ as well as in peripheral cells from $\mathrm{AD}$ subjects $[81,82]$. The brain's reduction in $\alpha$-ketoglutarate dehydrogenase presence and activity was region specific and observed mainly in temporal cortex, parietal cortex, and hippocampus [83]. Very interestingly, the loss of $\alpha$-ketoglutarate-dehydrogenase-positive neurons could be correlated to the total loss of neurons, suggesting a possible reason for the selective vulnerability in $\mathrm{AD}$ brain [84]. In the central nervous system, the high metabolic demand can lead to a higher level of oxidative stress via the production of free radicals. KGDH is sensitive to a wide range of oxidants. Under pathological conditions, $\mathrm{A} \beta$ further increases oxidative stress leading directly or indirectly to a decline in the activity of $\mathrm{KGDH}[85,86]$.

5.3.2. $A B A D$. The involvement of mitochondria in the pathogenic pathway of $A \beta$ was confirmed by specific binding of $\mathrm{A} \beta$ and $\mathrm{A} \beta \mathrm{PP}$ to mitochondrial proteins which causes energy impairment and cell physiology defects. Firstly, $\mathrm{A} \beta$ specifically binds to the mitochondrial $\mathrm{A} \beta$-binding alcohol dehydrogenase (ABAD) [4], a mitochondrial matrix protein which is upregulated in the temporal lobe of $\mathrm{AD}$ patients as well as in A $\beta P P$ transgenic mice [87-89]. The $\mathrm{A} \beta$-ABAD interaction caused elevated reactive oxygen species (ROS) production and cell death as well as spatial learning and memory deficits in 5-month-old $\mathrm{A} \beta \mathrm{PP} / \mathrm{ABAD}$ double-transgenic mice. The investigation of the crystal structure of $\mathrm{ABAD}-\mathrm{A} \beta$ demonstrated that the formation of the complex prevents the binding of $\mathrm{NAD}^{+}$to $\mathrm{ABAD}$, thereby changing mitochondrial membrane permeability [90] and reducing the activities of respiratory enzymes [4] which then may lead to mitochondrial failure. ABAD, a member of the short-chain dehydrogenase/reductase family, shows enzymatic activity toward a broad array of substrates including $n$-isopropanol and beta-estradiol. Thus, ABAD is important for mitochondrial function via facilitation of ketone body utilization by promoting the generation of acetyl-CoA to feed into the TCA cycle, an effect that is particularly important in situations of stress.

5.3.3. $m t D N A$. Some of the alterations that are found in mitochondrial function in $\mathrm{AD}$ have been attributed to mutations of mtDNA [91]. Although most mitochondrial 


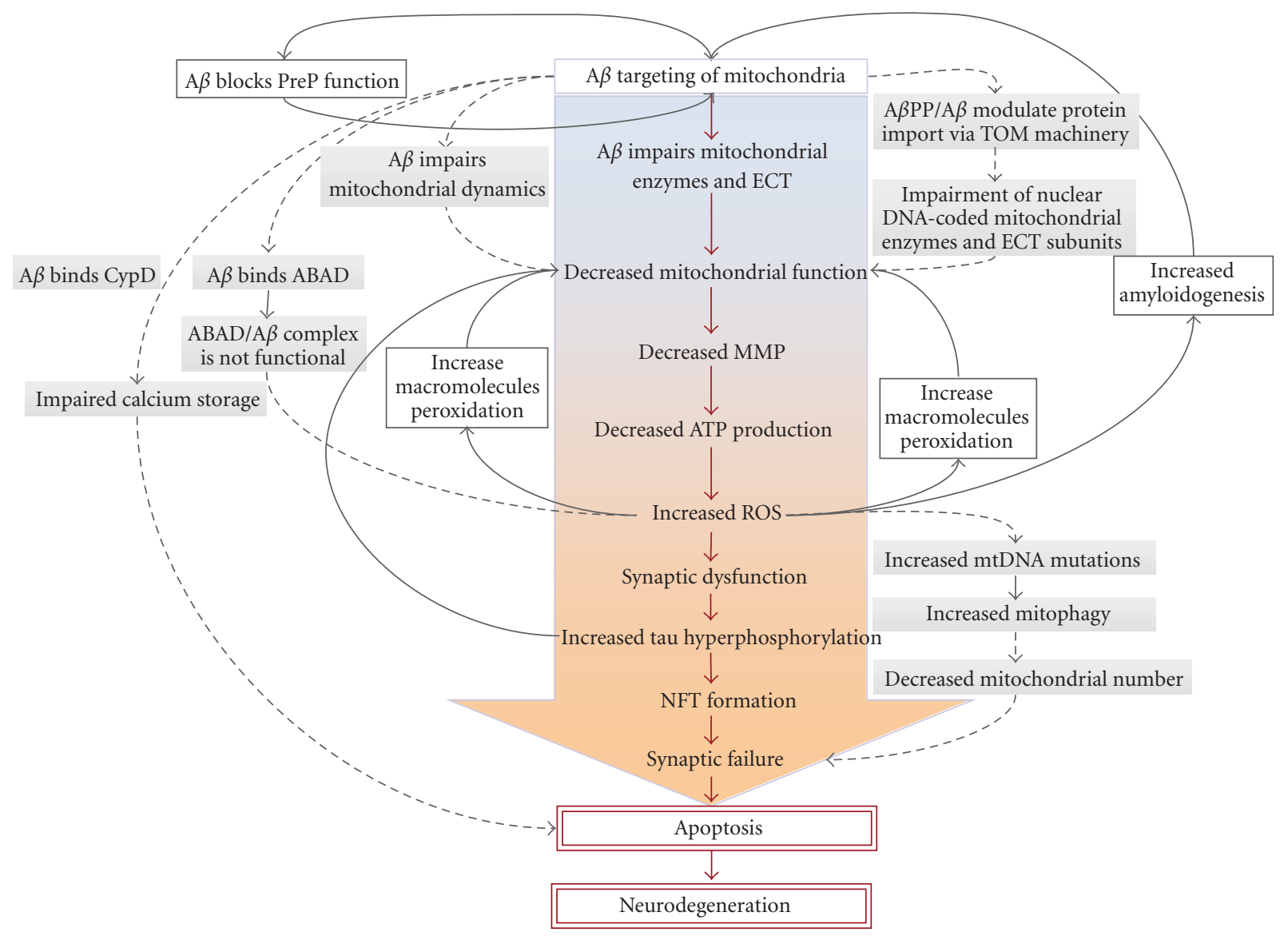

FIgURE 3: A hypothetical sequence of the pathogenic steps of the Alzheimer mitochondrial cascade hypothesis. The main cytotoxic pathway of $\mathrm{A} \beta$ (red arrows) involves $\mathrm{A} \beta$-induced mitochondrial function, increased ROS production, activation of neurofibrillary tangles (NFT) formation, synaptic failure, and neurodegeneration. Several other pathways feed this cascade via feeding back (black arrows) or forward (dashed arrows) revealing several vicious cycles within a larger vicious cycle. All of them, once set in motion, amplify their own processes, thus accelerating the development of AD.

proteins are encoded by the nuclear genome, mitochondria contain many copies of their own DNA that encodes for 13 polypeptide complexes of the respiratory chain. The increased number of mtDNA mutations can be explained by the proximity of mtDNA to oxidative stress generated by the respiratory chain itself, the lack of mtDNA to any protective histone covering, and a deficient repair mechanism compared to nuclear DNA. Therefore, mitochondria themselves are extremely sensitive to oxidative stress. For instance, mtDNA np4336 mutation in the tRNAGln gene was reported in sporadic AD patients [91-95]. In addition, it was shown that $\mathrm{AD}$ brains exhibited a striking increase in a 1,112-np mtDNA control region, an element known to be involved in mtDNA transcription and/or replication [96]; mutations in this region may be responsible for a decreased number of mitochondria. In the light of these data, a mitochondria cascade hypothesis was developed to explain the prevalence of $\mathrm{AD}$ by hypothesising that the pathology will easily develop when a mitochondria starting line, in conjunction with genetic and environmental factors, exhibits increased mtDNA mutations (Figure 3).

5.3.4. PreP. Several enzymes were identified to degrade A $\beta$. Neural endopeptidase (NEP) was shown responsible for the extracellular degradation of $\mathrm{A} \beta$ [97], while the two members of the pitrilysin oligopeptidase family, human insulin degrading enzyme (IDE) and presequence protease $(\mathrm{PreP})$, are responsible for the intracellular degradation of $\mathrm{A} \beta$. PreP is a metalloprotease containing an inverted zincbinding motif and was first identified in Arabidopsis thaliana as the enzyme responsible for mitochondrial degradation of targeting peptides up to 65 amino acids [98-100]. Intramitochondrial localization studies demonstrated PreP to be localized within the mitochondrial matrix [101, 102]. In case, $\mathrm{A} \beta$ reaches the matrix, it can be degraded by PreP (Figure 2). Two highly conserved cysteines (Cys527 and Cys90) are able to form a disulphide bridge in oxidizing condition, 
locking PreP in an inactive form. Since oxidizing conditions are present with high amount of $A \beta$ in mitochondria, this may prevent the clearance of $A \beta$ (Figure 2), exacerbating mitochondrial dysfunctions by accelerating its interactions with CypD and/or ABAD [37].

\section{Conclusion}

Rigorous scientific research has identified multiple mechanisms of $A \beta$ interaction with mitochondria at different mitochondrial compartments: the outer mitochondrial membrane, intermembrane space, inner mitochondrial membrane, and the matrix. With regard to the involvement of $\mathrm{A} \beta$-induced mitochondrial dysfunction in $\mathrm{AD}$ pathogenesis, a vicious cycle as well as several vicious circles within the cycle, each accelerating the other, can be drawn emphasizing the Alzheimer mitochondrial cascade hypothesis (Figure 3). $\mathrm{A} \beta \mathrm{PP}$ and/or $\mathrm{A} \beta$ may block mitochondrial translocation of nuclear-encoded proteins [27], such as components of the ETC [103-106], impairing mitochondrial function. Intramitochondrial $\mathrm{A} \beta$ is able to perturb mitochondrial function in several ways by directly influencing ETC complex activities [1], impairing mitochondrial dynamics [6] or disturbing calcium storage $[107,108]$, thus increasing apoptotic pathways [64], as well as via interaction with CypD. Moreover, $A \beta$ interacts with mitochondrial matrix components, such as enzymes of the Krebs cycle [109] and ABAD [87, 110], as well as PreP [37]. An improper mitochondrial complex function leads to a decreased mitochondrial membrane potential of the organelle [111], impairing ATP formation $[3,59,112$ 118]. Increased ROS levels act at multiple levels to impair mitochondrial function: they induce mtDNA mutations [91] that consequently negatively influence mitochondrial function [119], enhance $A \beta$ production by guiding $A \beta P P$ cleavage pathway toward the amyloidogenesis [120], increase lipid peroxidation [121, 122], activate mitophagy [123], leading to a reduced mitochondrial number [123], and augment tau hyperphosphorylation and NFT formation impairing organelle trafficking and neuronal function finally leading to apoptosis.

Finally, the critical role of mitochondria in the early pathogenesis of $\mathrm{AD}$ may make them attractive as a preferential target for treatment strategies. Transgenic mice modelling some pathological aspects are hence very valuable in monitoring therapeutic interventions at the mitochondrial level. In agreement, recent data suggest that natural plants such as a standardized Ginkgo biloba extract or the green tea component epigallocatechin-3-gallate may be promising treatment strategies. Of note, in addition to their antioxidative properties, these compounds stabilize mitochondrial functions such as the mitochondrial membrane potential, ATP levels, and mitochondrial respiratory complexes [124127]. Moreover, in APP transgenic mouse models, an antiamyloidogenic effect of these compounds was reported by inhibiting amyloid fibril formation either by a direct interaction with $\mathrm{A} \beta[128,129]$ or indirectly by reducing ROS levels [127]. However, the precise actions and, in particular, the mitochondrial targets of these drugs at the molecular level are unclear and need further clarification. In view of the increasing interest in mitochondrial protection as a treatment strategy in dementia, besides strategies with regard to the treatment and/or removal of both $A \beta$ and tau pathology, the findings of a substantial protection of mitochondria against $\mathrm{A} \beta$-induced dysfunction deserve further attention.

\section{References}

[1] V. Rhein, X. Song, A. Wiesner et al., "Amyloid- $\beta$ and tau synergistically impair the oxidative phosphorylation system in triple transgenic Alzheimer's disease mice," Proceedings of the National Academy of Sciences of the United States of America, vol. 106, no. 47, pp. 20057-20062, 2010.

[2] A. Eckert, S. Hauptmann, I. Scherping et al., "Oligomeric and fibrillar species of $\beta$-amyloid (A $\beta 42)$ both impair mitochondrial function in P301L tau transgenic mice," Journal of Molecular Medicine, vol. 86, no. 11, pp. 1255-1267, 2008.

[3] S. Hauptmann, I. Scherping, S. Dröse et al., "Mitochondrial dysfunction: an early event in Alzheimer pathology accumulates with age in AD transgenic mice," Neurobiology of Aging, vol. 30, no. 10, pp. 1574-1586, 2009.

[4] J. W. Lustbader, M. Cirilli, C. Lin et al., "ABAD directly links Abeta to mitochondrial toxicity in Alzheimer's disease," Science, vol. 304, pp. 448-452, 2004.

[5] B. Su, X. Wang, A. Nunomura et al., "Oxidative stress signaling in Alzheimer's disease," Current Alzheimer Research, vol. 5, no. 6, pp. 525-532, 2008.

[6] X. Wang, BO. Su, S. L. Siedlak et al., "Amyloid- $\beta$ overproduction causes abnormal mitochondrial dynamics via differential modulation of mitochondrial fission/fusion proteins," Proceedings of the National Academy of Sciences of the United States of America, vol. 105, no. 49, pp. 19318-19323, 2008.

[7] P. I. Moreira, M. S. Santos, and C. R. Oliveira, "Alzheimer's disease: a lesson from mitochondrial dysfunction," Antioxidants and Redox Signaling, vol. 9, no. 10, pp. 1621-1630, 2007.

[8] P. I. Moreira, M. S. Santos, C. R. Oliveira et al., "Alzheimer disease and the role of free radicals in the pathogenesis of the disease," CNS and Neurological Disorders-Drug Targets, vol. 7, no. 1, pp. 3-10, 2008.

[9] W. E. Müller, A. Eckert, C. Kurz, G. P. Eckert, and K. Leuner, "Mitochondrial dysfunction: common final pathway in brain aging and Alzheimer's disease-therapeutic aspects," Molecular Neurobiology, vol. 41, pp. 159-171, 2010.

[10] K. Leuner, S. Hauptmann, R. Abdel-Kader et al., "Mitochondrial dysfunction: the first domino in brain aging and Alzheimer's disease?" Antioxidants and Redox Signaling, vol. 9, no. 10, pp. 1659-1675, 2007.

[11] A. Eckert, K. L. Schulz, V. Rhein, and J. Götz, "Convergence of amyloid-beta and tau pathologies on mitochondria in vivo," Molecular Neurobiology, vol. 41, pp. 107-114, 2010.

[12] P. F. Pavlov, B. Wiehager, J. Sakai et al., "Mitochondrial gamma-secretase participates in the metabolism of mitochondria-associated amyloid precursor protein," The FASEB Journal, vol. 25, pp. 78-88, 2011.

[13] H. K. Anandatheerthavarada, G. Biswas, M. A. Robin, and N. G. Avadhani, "Mitochondrial targeting and a novel transmembrane arrest of Alzheimer's amyloid precursor protein impairs mitochondrial function in neuronal cells," Journal of Cell Biology, vol. 161, no. 1, pp. 41-54, 2003.

[14] K. Sambamurti, L. M. Refolo, J. Shioi, M. A. Pappolla, and N. K. Robakis, "The Alzheimer's amyloid precursor is cleaved 
intracellularly in the trans-golgi network or in a post-golgi compartment," Annals of the New York Academy of Sciences, vol. 674, pp. 118-128, 1992.

[15] T. M. J. Allinson, E. T. Parkin, A. J. Turner, and N. M. Hooper, "ADAMs family members as amyloid precursor protein alpha-secretases," Journal of Neuroscience Research, vol. 74, no. 3, pp. 342-352, 2003.

[16] J. Götz and L. M. Ittner, "Animal models of Alzheimer's disease and frontotemporal dementia," Nature Reviews Neuroscience, vol. 9, no. 7, pp. 532-544, 2008.

[17] D. Edbauer, E. Winkler, J. T. Regula, B. Pesold, H. Steiner, and C. Haass, "Reconstitution of $\gamma$-secretase activity," Nature Cell Biology, vol. 5, no. 5, pp. 486-488, 2003.

[18] D. J. Selkoe, "Alzheimer's disease is a synaptic failure," Science, vol. 298, no. 5594, pp. 789-791, 2002.

[19] C. Haass, A. Y. Hung, M. G. Schlossmacher, D. B. Teplow, and D. J. Selkoe, " $\beta$-Amyloid peptide and a $3-\mathrm{kDa}$ fragment are derived by distinct cellular mechanisms," Journal of Biological Chemistry, vol. 268, no. 5, pp. 3021-3024, 1993.

[20] R. Vassar, B. D. Bennett, S. Babu-Khan et al., " $\beta$-Secretase cleavage of Alzheimer's amyloid precursor protein by the transmembrane aspartic protease BACE," Science, vol. 286, no. 5440, pp. 735-741, 1999.

[21] P. G. Ulery, J. Beers, I. Mikhailenko et al., "Modulation of $\beta$-amyloid precursor protein processing by the low density lipoprotein receptor-related protein (LRP). Evidence that LRP contributes to the pathogenesis of Alzheimer's disease," Journal of Biological Chemistry, vol. 275, no. 10, pp. 74107415, 2000.

[22] J. A. Cam, C. V. Zerbinatti, Y. Li, and G. Bu, "Rapid endocytosis of the low density lipoprotein receptor-related protein modulates cell surface distribution and processing of the $\beta$-amyloid precursor protein," Journal of Biological Chemistry, vol. 280, no. 15, pp. 15464-15470, 2005.

[23] J. A. Cam, C. V. Zerbinatti, J. M. Knisely, S. Hecimovic, Y. $\mathrm{Li}$, and $\mathrm{G} . \mathrm{Bu}$, "The low density lipoprotein receptor-related protein $1 \mathrm{~B}$ retains $\beta$-amyloid precursor protein at the cell surface and reduces amyloid- $\beta$ peptide production," Journal of Biological Chemistry, vol. 279, no. 28, pp. 29639-29646, 2004.

[24] Y. Li, W. Lu, M. P. Marzolo, and G. Bu, "Differential functions of members of the low density lipoprotein receptor family suggested by their distinct endocytosis rates," Journal of Biological Chemistry, vol. 276, no. 21, pp. 18000-18006, 2001.

[25] O. M. Andersen, J. Reiche, V. Schmidt et al., "Neuronal sorting protein-related receptor sorLA/LR11 regulates processing of the amyloid precursor protein," Proceedings of the National Academy of Sciences of the United States of America, vol. 102, no. 38, pp. 13461-13466, 2005.

[26] R. Spoelgen, C. A. F. Von Arnim, A. V. Thomas et al., "Interaction of the cytosolic domains of sorLA/LR11 with the amyloid precursor protein (APP) and $\beta$-secretase $\beta$-site APPcleaving enzyme," Journal of Neuroscience, vol. 26, no. 2, pp. 418-428, 2006.

[27] L. Devi, B. M. Prabhu, D. F. Galati, N. G. Avadhani, and H. K. Anandatheerthavarada, "Accumulation of amyloid precursor protein in the mitochondrial import channels of human Alzheimer's disease brain is associated with mitochondrial dysfunction," Journal of Neuroscience, vol. 26, no. 35, pp. 9057-9068, 2006.

[28] M. Manczak, T. S. Anekonda, E. Henson, B. S. Park, J. Quinn, and P. H. Reddy, "Mitochondria are a direct site of $\mathrm{A} \beta$ accumulation in Alzheimer's disease neurons: implications for free radical generation and oxidative damage in disease progression," Human Molecular Genetics, vol. 15, no. 9, pp. 1437-1449, 2006.

[29] R. H. Takahashi, E. E. Nam, M. Edgar, and G. K. Gouras, "Alzheimer $\beta$-amyloid peptides: normal and abnormal localization," Histology and Histopathology, vol. 17, no. 1, pp. 239246, 2002.

[30] C. Caspersen, N. Wang, J. Yao et al., "Mitochondrial A $\beta$ : a potential focal point for neuronal metabolic dysfunction in Alzheimer's disease," FASEB Journal, vol. 19, no. 14, pp. 2040-2041, 2005.

[31] P. Fernández-Vizarra, A. P. Fernández, S. Castro-Blanco et al., "Intra- and extracellular $\mathrm{A} \beta$ and PHF in clinically evaluated cases of Alzheimer's disease," Histology and Histopathology, vol. 19, no. 3, pp. 823-844, 2004.

[32] T. Fujiwara, K. Oda, S. Yokota, A. Takatsuki, and Y. Ikehara, "Brefeldin A causes disassembly of the Golgi complex and accumulation of secretory proteins in the endoplasmic reticulum," Journal of Biological Chemistry, vol. 263, no. 34, pp. 18545-18552, 1988.

[33] C. G. Glabe and R. Kayed, "Common structure and toxic function of amyloid oligomers implies a common mechanism of pathogenesis," Neurology, vol. 66, no. 2, pp. S74-S78, 2006.

[34] P. H. Reddy and M. F. Beal, "Amyloid beta, mitochondrial dysfunction and synaptic damage: implications for cognitive decline in aging and Alzheimer's disease," Trends in Molecular Medicine, vol. 14, no. 2, pp. 45-53, 2008.

[35] M. A. Simmons and C. R. Schneider, "Amyloid $\beta$ peptides act directly on single neurons," Neuroscience Letters, vol. 150, no. 2, pp. 133-136, 1993.

[36] N. Arispe, E. Rojas, and H. B. Pollard, "Alzheimer disease amyloid $\beta$ protein forms calcium channels in bilayer membranes: blockade by tromethamine and aluminum," Proceedings of the National Academy of Sciences of the United States of America, vol. 90, no. 2, pp. 567-571, 1993.

[37] N. Alikhani, M. Ankarcrona, and E. Glaser, "Mitochondria and Alzheimer's disease: amyloid- $\beta$ peptide uptake and degradation by the presequence protease, hPreP," Journal of Bioenergetics and Biomembranes, vol. 41, no. 5, pp. 447-451, 2009.

[38] C. A. Hansson Petersen, N. Alikhani, H. Behbahani et al., "The amyloid $\beta$-peptide is imported into mitochondria via the TOM import machinery and localized to mitochondrial cristae," Proceedings of the National Academy of Sciences of the United States of America, vol. 105, no. 35, pp. 13145-13150, 2008.

[39] M. P. Mattson and T. Magnus, "Ageing and neuronal vulnerability," Nature Reviews Neuroscience, vol. 7, no. 4, pp. 278-294, 2006.

[40] R. S. Balaban, S. Nemoto, and T. Finkel, "Mitochondria, oxidants, and aging," Cell, vol. 120, no. 4, pp. 483-495, 2005.

[41] G. Benzi, O. Pastoris, F. Marzatico, R. F. Villa, F. Dagani, and D. Curti, "The mitochondrial electron transfer alteration as a factor involved in the brain aging," Neurobiology of Aging, vol. 13, no. 3, pp. 361-368, 1992.

[42] P. H. Reddy, "Mitochondrial dysfunction in aging and Alzheimer's disease: strategies to protect neurons," Antioxidants and Redox Signaling, vol. 9, no. 10, pp. 1647-1658, 2007.

[43] P. I. Moreira, A. I. Duarte, M. S. Santos, A. C. Rego, and C. R. Oliveira, "An integrative view of the role of oxidative stress, mitochondria and insulin in Alzheimer's disease," Journal of Alzheimer's Disease, vol. 16, no. 4, pp. 741-761, 2009. 
[44] D. Sirk, Z. Zhu, J. S. Wadia et al., "Chronic exposure to sub-lethal beta-amyloid (A $\beta)$ inhibits the import of nuclearencoded proteins to mitochondria in differentiated PC12 cells," Journal of Neurochemistry, vol. 103, no. 5, pp. 1989 2003, 2007.

[45] K. Okamoto and J. M. Shaw, "Mitochondrial morphology and dynamics in yeast and multicellular eukaryotes," Annual Review of Genetics, vol. 39, pp. 503-536, 2005.

[46] H. Chen, A. Chomyn, and D. C. Chan, "Disruption of fusion results in mitochondrial heterogeneity and dysfunction," Journal of Biological Chemistry, vol. 280, no. 28, pp. 2618526192, 2005.

[47] H. Chen, S. A. Detmer, A. J. Ewald, E. E. Griffin, S. E. Fraser, and D. C. Chan, "Mitofusins Mfn1 and Mfn2 coordinately regulate mitochondrial fusion and are essential for embryonic development," Journal of Cell Biology, vol. 160, no. 2, pp. 189-200, 2003.

[48] H. Chen, J. M. McCaffery, and D. C. Chan, "Mitochondrial fusion protects against neurodegeneration in the cerebellum," Cell, vol. 130, no. 3, pp. 548-562, 2007.

[49] R. H. Baloh, R. E. Schmidt, A. Pestronk, and J. Milbrandt, "Altered axonal mitochondrial transport in the pathogenesis of Charcot-Marie-Tooth disease from mitofusin 2 mutations," Journal of Neuroscience, vol. 27, no. 2, pp. 422-430, 2007.

[50] S. Hoppins, L. Lackner, and J. Nunnari, "The machines that divide and fuse mitochondria," Annual Review of Biochemistry, vol. 76, pp. 751-780, 2007.

[51] X. Wang, BO. Su, H. G. Lee et al., "Impaired balance of mitochondrial fission and fusion in Alzheimer's disease," Journal of Neuroscience, vol. 29, no. 28, pp. 9090-9103, 2009.

[52] B. Su, X. Wang, D. Bonda, G. Perry, M. Smith, and X. Zhu, "Abnormal mitochondrial dynamics-a novel therapeutic target for Alzheimer's disease?" Molecular Neurobiology, vol. 41, pp. 87-96, 2010.

[53] X. Wang, BO. Su, H. Fujioka, and X. Zhu, "Dynamin-like protein 1 reduction underlies mitochondrial morphology and distribution abnormalities in fibroblasts from sporadic Alzheimer's disease patients," American Journal of Pathology, vol. 173, no. 2, pp. 470-482, 2008.

[54] D. H. Cho, T. Nakamura, J. Fang et al., "S-nitrosylation of Drp1 mediates beta-amyloid-related mitochondrial fission and neuronal injury," Science, vol. 324, no. 5923, pp. 102-105, 2009.

[55] H. W. Querfurth and F. M. LaFerla, "Alzheimer's disease," New England Journal of Medicine, vol. 362, no. 4, pp. 329344, 2010.

[56] K. Schuessel, S. Schäfer, T. A. Bayer et al., "Impaired Cu/ZnSOD activity contributes to increased oxidative damage in APP transgenic mice," Neurobiology of Disease, vol. 18, no. 1, pp. 89-99, 2005.

[57] U. Keil, A. Bonert, C. A. Marques et al., "Amyloid $\beta$-induced changes in nitric oxide production and mitochondrial activity lead to apoptosis," Journal of Biological Chemistry, vol. 279, no. 48, pp. 50310-50320, 2004.

[58] F. Gillardon, W. Rist, L. Kussmaul et al., "Proteomic and functional alterations in brain mitochondria from $\mathrm{Tg} 2576$ mice occur before amyloid plaque deposition," Proteomics, vol. 7, no. 4, pp. 605-616, 2007.

[59] A. Eckert, S. Hauptmann, I. Scherping et al., "Soluble betaamyloid leads to mitochondrial defects in amyloid precursor protein and tau transgenic mice," Neurodegenerative Diseases, vol. 5, no. 3-4, pp. 157-159, 2008.
[60] V. Rhein, G. Baysang, S. Rao et al., "Amyloid-beta leads to impaired cellular respiration, energy production and mitochondrial electron chain complex activities in human neuroblastoma cells," Cellular and Molecular Neurobiology, vol. 29, no. 6-7, pp. 1063-1071, 2009.

[61] S. Oddo, A. Caccamo, J. D. Shepherd et al., "Triple-transgenic model of Alzheimer's Disease with plaques and tangles: intracellular A $\beta$ and synaptic dysfunction," Neuron, vol. 39, no. 3, pp. 409-421, 2003.

[62] J. Yao, R. W. Irwin, L. Zhao, J. Nilsen, R. T. Hamilton, and R. D. Brinton, "Mitochondrial bioenergetic deficit precedes Alzheimer's pathology in female mouse model of Alzheimer's disease," Proceedings of the National Academy of Sciences of the United States of America, vol. 106, no. 34, pp. 14670-14675, 2009.

[63] H. Du, L. Guo, F. Fang et al., "Cyclophilin D deficiency attenuates mitochondrial and neuronal perturbation and ameliorates learning and memory in Alzheimer's disease," Nature Medicine, vol. 14, no. 10, pp. 1097-1105, 2008.

[64] H. Du, L. Guo, W. Zhang, M. Rydzewska, and S. Yan, "Cyclophilin D deficiency improves mitochondrial function and learning/memory in aging Alzheimer disease mouse model," Neurobiology of Aging. In press.

[65] A. P. Halestrap, G. P. McStay, and S. J. Clarke, "The permeability transition pore complex: another view," Biochimie, vol. 84, no. 2-3, pp. 153-166, 2002.

[66] N. Zamzami, N. Larochette, and G. Kroemer, "Mitochondrial permeability transition in apoptosis and necrosis," Cell Death and Differentiation, vol. 12, no. 2, pp. 1478-1480, 2005.

[67] M. Crompton, E. Barksby, N. Johnson, and M. Capano, "Mitochondrial intermembrane junctional complexes and their involvement in cell death," Biochimie, vol. 84, no. 2-3, pp. 143-152, 2002.

[68] A. P. Halestrap, "Calcium, mitochondria and reperfusion injury: a pore way to die," Biochemical Society Transactions, vol. 34, no. 2, pp. 232-237, 2006.

[69] P. Bernardi, A. Krauskopf, E. Basso et al., "The mitochondrial permeability transition from in vitro artifact to disease target," FEBS Journal, vol. 273, pp. 2077-2099, 2006.

[70] K. W. Kinnally, P. M. Peixoto, S. -Y. Ryu, and L. M. Dejean, "Is MPTP the gatekeeper for necrosis, apoptosis, or both?" Biochimica et Biophysica Acta. In press.

[71] X. Liu, C. N. Kim, J. Yang, R. Jemmerson, and X. Wang, "Induction of apoptotic program in cell-free extracts: requirement for dATP and cytochrome c," Cell, vol. 86, no. 1, pp. 147-157, 1996.

[72] H. Zou, W. J. Henzel, X. Liu, A. Lutschg, and X. Wang, "Apaf-1, a human protein homologous to C. elegans CED4, participates in cytochrome c-dependent activation of caspase-3," Cell, vol. 90, no. 3, pp. 405-413, 1997.

[73] S. A. Susin, H. K. Lorenzo, N. Zamzami et al., "Mitochondrial release of caspase- 2 and -9 during the apoptotic process," Journal of Experimental Medicine, vol. 189, no. 2, pp. 381393, 1999.

[74] C. Adrain, E. M. Creagh, and S. J. Martin, "Apoptosisassociated release of Smac/DIABLO from mitochondria requires active caspases and is blocked by Bcl-2," EMBO Journal, vol. 20, no. 23, pp. 6627-6636, 2001.

[75] L. Y. Li, X. Luo, and X. Wang, "Endonuclease G is an apoptotic DNase when released from mitochondria," Nature, vol. 412, no. 6842, pp. 95-99, 2001.

[76] R. A. Eliseev, G. Filippov, J. Velos et al., "Role of cyclophilin $\mathrm{D}$ in the resistance of brain mitochondria to the permeability 
transition," Neurobiology of Aging, vol. 28, no. 10, pp. 15321542, 2007.

[77] G. Hajnóczky and J. B. Hoek, "Cell signaling: mitochondrial longevity pathways," Science, vol. 315, no. 5812, pp. 607-609, 2007.

[78] E. K. Perry, R. H. Perry, and B. E. Tomlinson, "Coenzyme Aacetylating enzymes in Alzheimer's disease: possible cholinergic 'compartment' of pyruvate dehydrogenase," Neuroscience Letters, vol. 18, no. 1, pp. 105-110, 1980.

[79] S. Sorbi, E. D. Bird, and J. P. Blass, "Decreased pyruvate dehydrogenase complex activity in Huntington and Alzheimer brain," Annals of Neurology, vol. 13, no. 1, pp. 72-78, 1983.

[80] G. E. Gibson, K. F. R. Sheu, and J. P. Blass, "Abnormalities of mitochondrial enzymes in Alzheimer disease," Journal of Neural Transmission, vol. 105, no. 8-9, pp. 855-870, 1998.

[81] G. E. Gibson, K. F. R. Sheu, J. P. Blass et al., "Reduced activities of thiamine-dependent enzymes in the brains and peripheral tissues of patients with Alzheimer's disease," Archives of Neurology, vol. 45, no. 8, pp. 836-840, 1988.

[82] K. F. R. Sheu, A. J. L. Cooper, K. Koike, M. Koike, J. G. Lindsay, and J. P. Blass, "Abnormality of the $\alpha$ ketoglutarate dehydrogenase complex in fibroblasts from familial Alzheimer's disease," Annals of Neurology, vol. 35, no. 3, pp. 312-318, 1994.

[83] F. Mastrogiacoma, J. G. Lindsay, L. Bettendorff, J. Rice, and S. H. Kish, "Brain protein and alpha-ketoglutarate dehydrogenase complex activity in Alzheimer's disease," Annals of Neurology, vol. 39, pp. 592-598, 1996.

[84] L. W. Ko, K. F. R. Sheu, H. T. Thaler, W. R. Markesbery, and J. P. Blass, "Selective loss of KGDHC-enriched neurons in Alzheimer temporal cortex: does mitochondrial variation contribute to selective vulnerability?" Journal of Molecular Neuroscience, vol. 17, no. 3, pp. 361-369, 2001.

[85] G. E. Gibson, A. Starkov, J. P. Blass, R. R. Ratan, and M. F. Beal, "Cause and consequence: mitochondrial dysfunction initiates and propagates neuronal dysfunction, neuronal death and behavioral abnormalities in age-associated neurodegenerative diseases," Biochimica et Biophysica Acta, vol. 1802, no. 1, pp. 122-134, 2010.

[86] C. S. Casley, L. Canevari, J. M. Land, J. B. Clark, and M. A. Sharpe, " $\beta$-Amyloid inhibits integrated mitochondrial respiration and key enzyme activities," Journal of Neurochemistry, vol. 80, no. 1, pp. 91-100, 2002.

[87] S. D. Yan, J. Fu, C. Soto et al., "An intracellular protein that binds amyloid- $\beta$ peptide and mediates neurotoxicity in Alzheimer's disease," Nature, vol. 389, no. 6652, pp. 689-695, 1997.

[88] G. Y. Wen, S. Y. Yang, W. Kaczmarski, X. Y. He, and K. S. Pappas, "Presence of hydroxysteroid dehydrogenase type 10 in amyloid plaques (APs) of Hsiao's APP-Sw transgenic mouse brains, but absence in APs of Alzheimer's disease brains," Brain Research, vol. 954, no. 1, pp. 115-122, 2002.

[89] X. Y. He, G. Y. Wen, G. Merz et al., “Abundant type $1017 \beta$ hydroxysteroid dehydrogenase in the hippocampus of mouse Alzheimer's disease model," Molecular Brain Research, vol. 99, no. 1, pp. 46-53, 2002.

[90] A. M. Aleardi, G. Benard, O. Augereau et al., "Gradual alteration of mitochondrial structure and function by $\beta$-amyloids: importance of membrane viscosity changes, energy deprivation, reactive oxygen species production, and cytochrome c release," Journal of Bioenergetics and Biomembranes, vol. 37, no. 4, pp. 207-225, 2005.
[91] J. M. Shoffner, M. D. Brown, A. Torroni et al., "Mitochondrial DNA variants observed in Alzheimer disease and Parkinson disease patients," Genomics, vol. 17, no. 1, pp. 171-184, 1993.

[92] M. D. Brown, J. M. Shoffher, Y. L. Kim et al., "Mitochondrial DNA sequence analysis of four Alzheimer's and Parkinson's disease patients," American Journal of Medical Genetics, vol. 61, no. 3, pp. 283-289, 1996.

[93] T. Hutchin and G. Cortopassi, "A mitochondrial DNA clone is associated with increased risk for Alzheimer disease," Proceedings of the National Academy of Sciences of the United States of America, vol. 92, no. 15, pp. 6892-6895, 1995.

[94] C. Tysoe, D. Robinson, C. Brayne et al., "The tRNAGln 4336 mitochondrial DNA variant is not a high penetrance mutation which predisposes to dementia before the age of 75 years," Journal of Medical Genetics, vol. 33, no. 12, pp. 10021006, 1996.

[95] R. Egensperger, S. Kösel, N. M. Schnopp, P. Mehraein, and M. B. Graeber, "Association of the mitochondrial tRNA(A4336G) mutation with Alzheimer's and Parkinson's diseases," Neuropathology and Applied Neurobiology, vol. 23, no. 4, pp. 315-321, 1997.

[96] P. E. Coskun, M. F. Beal, and D. C. Wallace, "Alzheimer's brains harbor somatic mtDNA control-region mutations that suppress mitochondrial transcription and replication," Proceedings of the National Academy of Sciences of the United States of America, vol. 101, no. 29, pp. 10726-10731, 2004.

[97] S. Sudoh, M. P. Frosch, and B. A. Wolf, "Differential effects of proteases involved in intracellular degradation of amyloid beta-protein between detergent-soluble and -insoluble pools in CHO-695 cells," Biochemistry, vol. 41, no. 4, pp. 10911099, 2002.

[98] A. Ståhl, P. Moberg, J. Ytterberg et al., "Isolation and identification of a novel mitochondrial metalloprotease (PreP) that degrades targeting presequences in plants," Journal of Biological Chemistry, vol. 277, no. 44, pp. 41931-41939, 2002.

[99] A. Ståhl, S. Nilsson, P. Lundberg et al., "Two novel targeting peptide degrading proteases, PrePs, in mitochondria and chloroplasts, so similar and still different," Journal of Molecular Biology, vol. 349, no. 4, pp. 847-860, 2005.

[100] P. Moberg, A. Ståh, S. Bhushan et al., "Characterization of a novel zinc metalloprotease involved in degrading targeting peptides in mitochondria and chloroplasts," Plant Journal, vol. 36, no. 5, pp. 616-628, 2003.

[101] S. W. Taylor, E. Fahy, B. Zhang et al., "Characterization of the human heart mitochondrial proteome," Nature Biotechnology, vol. 21, no. 3, pp. 281-286, 2003.

[102] A. Falkevall, N. Alikhani, S. Bhushan et al., "Degradation of the amyloid beta-protein by the novel mitochondrial peptidasome," Journal of Biological Chemistry, vol. 281, no. 39, pp. 29096-29104, 2006.

[103] W. D. Parker, C. M. Filley, and J. K. Parks, "Cytochrome oxidase deficiency in Alzheimer's disease," Neurology, vol. 40, no. 8, pp. 1302-1303, 1990.

[104] W. D. Parker and J. K. Parks, "Cytochrome c oxidase in Alzheimer's disease brain: purification and characterization," Neurology, vol. 45, no. 3 I, pp. 482-486, 1995.

[105] S. M. Cardoso, I. Santana, R. H. Swerdlow, and C. R. Oliveira, "Mitochondria dysfunction of Alzheimer's disease cybrids enhances A $\beta$ toxicity," Journal of Neurochemistry, vol. 89, no. 6, pp. 1417-1426, 2004.

[106] S. J. Kish, C. Bergeron, A. Rajput et al., "Brain cytochrome oxidase in Alzheimer's disease," Journal of Neurochemistry, vol. 59, no. 2, pp. 776-779, 1992. 
[107] R. J. Mark, Z. Pang, J. W. Geddes, K. Uchida, and M. P. Mattson, "Amyloid $\beta$-peptide impairs glucose transport in hippocampal and cortical neurons: involvement of membrane lipid peroxidation," Journal of Neuroscience, vol. 17, no. 3, pp. 1046-1054, 1997.

[108] M. P. Mattson, "Pathways towards and away from Alzheimer's disease," Nature, vol. 430, no. 7000, pp. 631-639, 2004.

[109] P. Bubber, V. Haroutunian, G. Fisch, J. P. Blass, and G. E. Gibson, "Mitochondrial abnormalities in Alzheimer brain: mechanistic implications," Annals of Neurology, vol. 57, no. 5, pp. 695-703, 2005.

[110] S. D. Yan, Y. Shi, A. Zhu et al., "Role of ERAB/L-3hydroxyacyl-coenzyme A dehydrogenase type II activity in A $\beta$-induced cytotoxicity," Journal of Biological Chemistry, vol. 274, no. 4, pp. 2145-2156, 1999.

[111] U. Keil, S. Hauptmann, A. Bonert, I. Scherping, A. Eckert, and W. E. Müller, "Mitochondrial dysfunction induced by disease relevant AbetaPP and tau protein mutations," Journal of Alzheimer's Disease, vol. 9, no. 2, pp. 139-146, 2006.

[112] M. T. Lin and M. F. Beal, "Mitochondrial dysfunction and oxidative stress in neurodegenerative diseases," Nature, vol. 443, no. 7113, pp. 787-795, 2006.

[113] A. Nunomura, G. Perry, G. Aliev et al., "Oxidative damage is the earliest event in Alzheimer disease," Journal of Neuropathology and Experimental Neurology, vol. 60, no. 8, pp. 759-767, 2001.

[114] P. H. Reddy and M. F. Beal, "Are mitochondria critical in the pathogenesis of Alzheimer's disease?" Brain Research Reviews, vol. 49, no. 3, pp. 618-632, 2005.

[115] P. I. Moreira, C. Carvalho, X. Zhu, M. A. Smith, and G. Perry, "Mitochondrial dysfunction is a trigger of Alzheimer's disease pathophysiology," Biochimica et Biophysica Acta, vol. 1802, no. 1, pp. 2-10, 2010.

[116] W. D. Parker, "Cytochrome oxidase deficiency in Alzheimer's disease," Annals of the New York Academy of Sciences, vol. 640, pp. 59-64, 1991.

[117] I. Maurer, S. Zierz, and H. J. Möller, "A selective defect of cytochrome c oxidase is present in brain of Alzheimer disease patients," Neurobiology of Aging, vol. 21, no. 3, pp. 455-462, 2000.

[118] R. L. Russell, S. L. Siedlak, A. K. Raina, J. M. Bautista, M. A. Smith, and G. Perry, "Increased neuronal glucose6-phosphate dehydrogenase and sulfhydryl levels indicate reductive compensation to oxidative stress in Alzheimer disease," Archives of Biochemistry and Biophysics, vol. 370, no. 2, pp. 236-239, 1999.

[119] R. H. Swerdlow, "Mitochondria in cybrids containing mtDNA from persons with mitochondriopathies," Journal of Neuroscience Research, vol. 85, no. 15, pp. 3416-3428, 2007.

[120] M. Newman, F. I. Musgrave, and M. Lardelli, "Alzheimer disease: amyloidogenesis, the presenilins and animal models," Biochimica et Biophysica Acta, vol. 1772, no. 3, pp. 285-297, 2007.

[121] E. Richartz, S. Noda, K. Schott, A. Günthner, P. Lewczuk, and M. Bartels, "Increased serum levels of CD95 in Alzheimer's disease," Dementia and Geriatric Cognitive Disorders, vol. 13, no. 3, pp. 178-182, 2002.

[122] K. Zarkovic, "4-Hydroxynonenal and neurodegenerative diseases," Molecular Aspects of Medicine, vol. 24, no. 4-5, pp. 293-303, 2003.

[123] K. Hirai, G. Aliev, A. Nunomura et al., "Mitochondrial abnormalities in Alzheimer's disease," Journal of Neuroscience, vol. 21, no. 9, pp. 3017-3023, 2001.
[124] R. Abdel-Kader, S. Hauptmann, U. Keil et al., "Stabilization of mitochondrial function by Ginkgo biloba extract (EGb 761)," Pharmacological Research, vol. 56, no. 6, pp. 493-502, 2007.

[125] A. Eckert, U. Keil, S. Kressmann et al., "Effects of EGb 761 Ginkgo biloba extract on mitochondrial function and oxidative stress," Pharmacopsychiatry, vol. 36, supplement 1, pp. S15-S23, 2003.

[126] A. Eckert, U. Keil, I. Scherping, S. Hauptmann, and W. E. Müller, "Stabilization of mitochondrial membrane potential and improvement of neuronal energy metabolism by Ginkgo biloba extract EGb 761," Annals of the New York Academy of Sciences, vol. 1056, pp. 474-485, 2005.

[127] V. Rhein, M. Giese, G. Baysang et al., "Ginkgo biloba extract ameliorates oxidative phosphorylation performance and rescues $\mathrm{A} \beta$-induced failure," PLos One, vol. 5, no. 8, Article ID e12359, 2010.

[128] S. Bastianetto, C. Ramassamy, S. Doré, Y. Christen, J. Poirier, and R. Quirion, "The ginkgo biloba extract (EGb 761) protects hippocampal neurons against cell death induced by $\beta$-amyloid," European Journal of Neuroscience, vol. 12, no. 6, pp. 1882-1890, 2000.

[129] Z. Yao, K. Drieu, and V. Papadopoulos, "The Ginkgo biloba extract EGb 761 rescues the PC12 neuronal cells from betaamyloid-induced cell death by inhibiting the formation of beta-amyloid-derived diffusible neurotoxic ligands," Brain Research, vol. 889, pp. 181-190, 2001. 


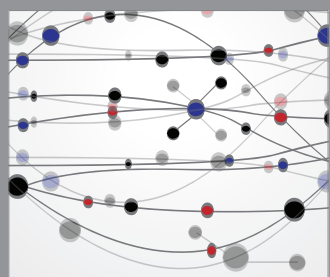

The Scientific World Journal
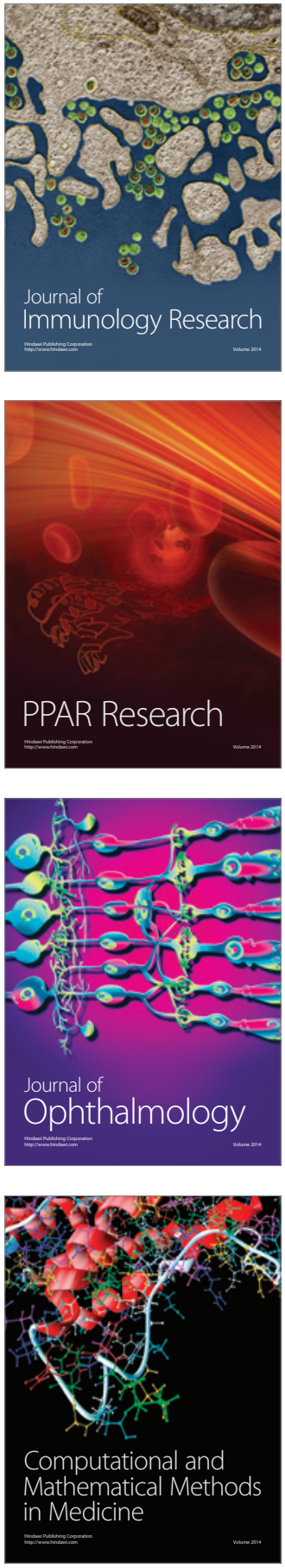

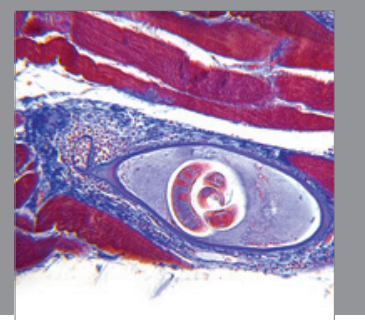

Gastroenterology

Research and Practice
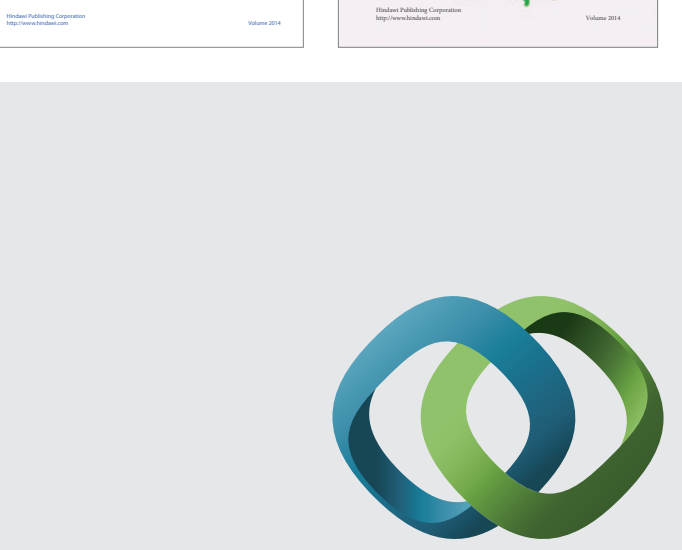

\section{Hindawi}

Submit your manuscripts at

http://www.hindawi.com
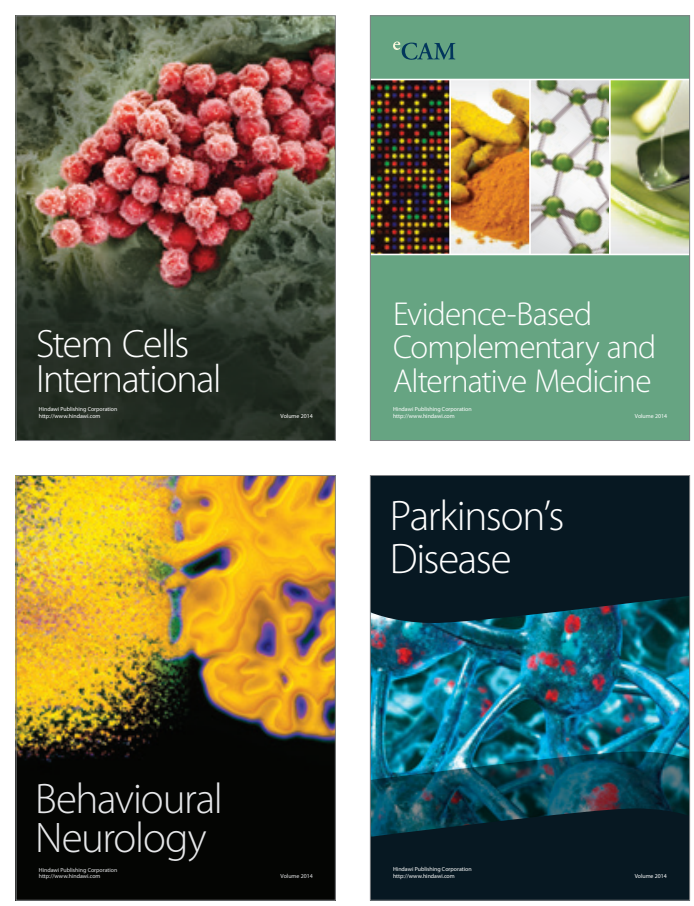

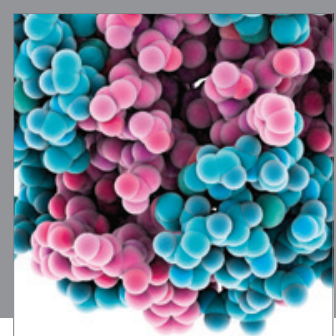

Journal of
Diabetes Research

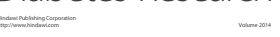

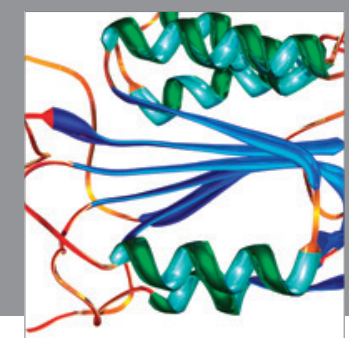

Disease Markers
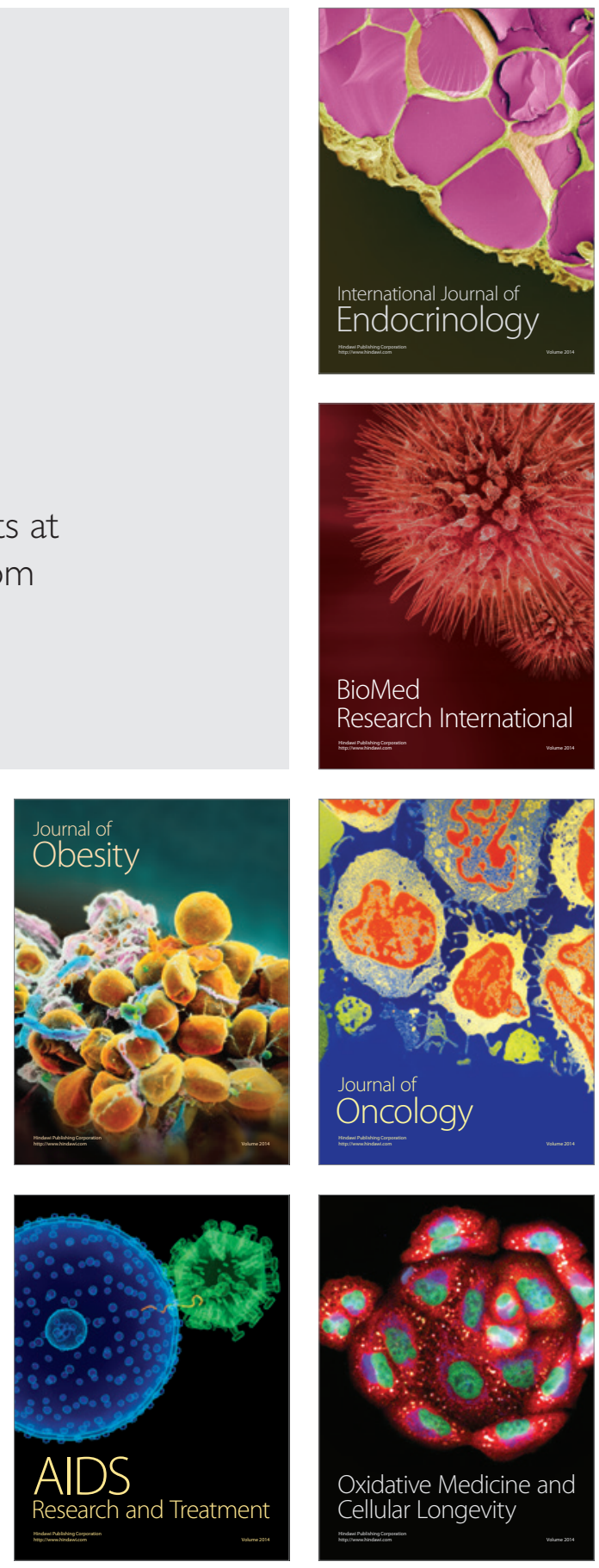